\title{
Infected Vaginal Hydrocele Due to a Septic Puncture-Aspiration: A Series of Seven Cases Collected at Yalgado Ouedraogo Teaching Hospital of Ouagadougou
}

\author{
Fasnéwindé A. Kaboré1, Moussa Kaboré1*, Bienvenue D. Ky¹, \\ Clôtaire Alexis Marie Kiemdiba Donega Yameogo', Brahima Kirakoya', Boukary Kabré1, \\ Moussa Bazongo², Barnabé Zango', Timothée Kambou ${ }^{3}$, Si Simon Traoré ${ }^{2}$ \\ ${ }^{1}$ Department of Urology, Yalgado Ouédraogo Teaching Hospital, Ouagadougou, Burkina Faso \\ ${ }^{2}$ Division of General Surgery, Yalgado Ouédraogo University Hospital, Ouagadougou, Burkina Faso \\ ${ }^{3}$ Department of Urology, Sanon Souro Teaching Hospital, Bobo Dioulasso, Burkina Faso \\ Email: *kaborefamd@me.com
}

Received 26 January 2016; accepted 8 March 2016; published 11 March 2016

Copyright (C) 2016 by authors and Scientific Research Publishing Inc.

This work is licensed under the Creative Commons Attribution International License (CC BY).

http://creativecommons.org/licenses/by/4.0/

c) (i) Open Access

\section{Abstract}

Objective: To describe diagnostic and therapeutic outcomes of infected vaginal hydrocele.Material and Methods: This is a retrospective descriptive study over a period of two years from June 2013 to May 2015 at the urological emergency department of Yalgado Ouédraogo University Hospital (CHU-YO). Results: We collected seven cases during the period of study. The average age of patients was 35 years. Two patients $(2 / 7)$ were from urban and five from rural areas. Five patients $(5 / 7)$ were married and two $(2 / 7)$ unmarried. Six patients $(6 / 7)$ were farmers and one $(1 / 7)$ was civil servent. Clinical examination findings were dominated by bilateral painful scrotal swelling and fever in all cases, a scrotal necrosis in two cases. The dominant indication of the punctureaspiration was discomfort during sexual intercourse (5/7). At the opening of the scrotum purulent fluid was aspirated in all cases, and we performed a unilateral orchidectomy in two cases. A hydrocelectomy was performed in all cases. The postoperative evolution was simple in all patients. Conclusion: The puncture-aspiration must be avoided because the risk of infection and the high recurrence rate.

\section{Keywords}

Vaginal Hydrocele, Infection, Hydrocelectomy

\footnotetext{
${ }^{*}$ Corresponding author.
}

How to cite this paper: Kaboré, F.A., et al. (2016) Infected Vaginal Hydrocele Due to a Septic Puncture-Aspiration: A Series of Seven Cases Collected at Yalgado Ouedraogo Teaching Hospital of Ouagadougou. Open Journal of Urology, 6, 32-35. 


\section{Introduction}

Vaginal hydrocele ( $\mathrm{VH})$ is an abnormal collection of a sterile serous fluid between the visceral and parietal layers of the tunica vaginalis testis [1]-[3]. It can be idiopathic or caused by an infection, a trauma, a varicocelectomy. VH is usually painless. The diagnosis of $\mathrm{VH}$ is clinical and can be confirmed by ultrasonography. The VH usually appears in middle aged or elderly men [2]. The VH is frequent in tropical countries due to endemic filariosis. VH is a commonest clinical manifestation of lymphatic filariasis. It has social, economic, sexual and psychological implications [4]. The infection of vaginal fluid can be done from epididymo-testicular infection [5]. Infection may also follow a septic puncture-aspiration. Hydrocele becomes an infected hydrocele which is a surgical emergency. The simple puncture-aspiration of hydrocele fluid is associated with high recurrence rate and should be avoided. The aim of this study was to describe the diagnosis and therapeutic characteristics of infected hydrocele caused by simple puncture-aspiration.

\section{Patients and Methods}

We conducted a retrospective descriptive study over a period of two years from June 2013 to May 2015 at the urological emergency unit of Yalgado Ouédraogo University Hospital (CHU-YO). Were included in the study, the patients with an infected idiopathic hydrocele in whom a notion of puncture-aspiration of hydrocele fluid was found in the interrogation. The puncture was performed in peripheral medical centers and patients were referred to our center after the infection of the VH. The puncture-aspiration was made in order to aspirate the hydrocele fluid but without injecting sclerosing product. The seven patients we collected were admitted for painful bilateral scrotal swelling after a septic puncture-aspiration. All the patients had given their informed consent for the study. The studied variables were age, the zone of residence, marital status, the profession, clinical examination findings, the bacteriological study of the fluid, the time evolution of hydrocele, the indication of the puncture, the treatment results and evolution.

\section{Results}

We collected seven cases during the period of study. The average age of patients was 35 years with range of 30 to 60 years. Two patients (2/7) were from urban and five from rural areas. Five patients (5/7) were married and two (2/7) unmarried. Six patients (6/7) were farmers and one was civil servent. Clinical examination findings were bilateral painful scrotal swelling and fever in all cases. A scrotal necrosis was found in two cases (Figure 1). Predominantly neutrophilic Leukocytosis was noted in four cases (4/7). The average time of evolution of hydrocele before puncture was 3 years. The indications of the puncture-aspiration were a discomfort during sexual intercourses (5/7) and patient request (2/5). At the opening of the scrotum purulent fluid was aspirated in all cases, and we performed a unilateral orchidectomy in two cases (2/7). A hydrocelectomy was performed in all cases. The bacteriological study of liquid has isolated a germ in five patients (5/7). The bacterium isolated

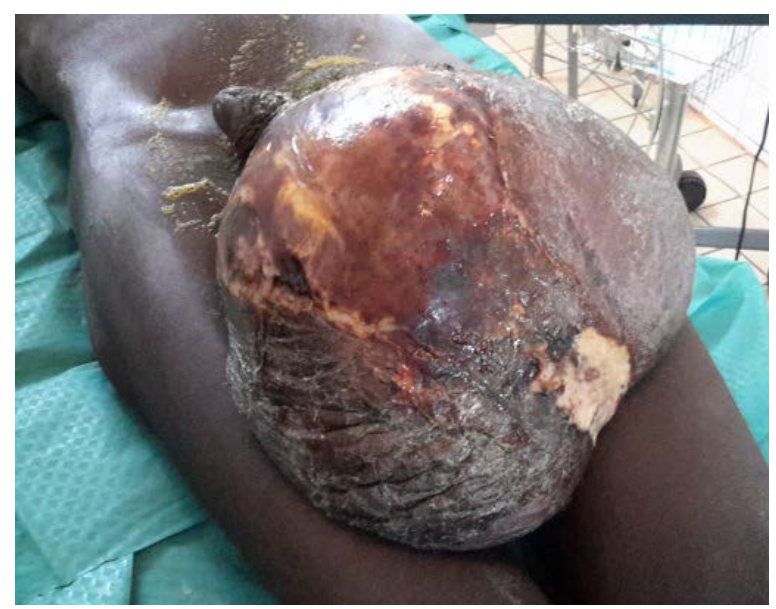

Figure 1. Bilateral infected hydrocele with scrotal necrosis after a septic puncture-aspiration. 
were Escherichia coli in three cases (3/5) and Klebsiella pneumoniae in two cases (2/5). Antibiotetherapy has been adapted to the antibiogram.After a six months follow-up the postoperative evolution was simple in all cases.

\section{Discussion}

The average age of patients was 35 years. This corresponds to a relatively young age. Gyapong M. et al. reported that the peak incidence of hydrocele is in the age group 19 - 34 [6]. An age where the individual actively expresses his social and sexual identity [6]. VH is normally painless except in an infected hydrocele or hydrocele associated with an epididymo-testicular painful pathology [7].

Several technics are available for the treatment of idiopathic VH. The two main technics are the plication of vaginal according to Lord and the hydrocelectomy [5]-[8]. In the hydrocelectomy a resection of the vaginal is performed followed by hemostatic continuous suture. There are other technics such as fenestration of vaginal and aspiration followed by sclerotherapy which involves the injection of sclerosing products in the vaginal such as tetracycline, alcohol [1]-[10].

Sclerotherapy seems to be minimally invasive approach with few postoperative complications even if the long-term effect on fertility is not yet well elucidated [1] [9] [10]. Each technic has its advantages and disadvantages but the gold standard of idiopathic hydrocele treatment remains hydrocelectomy [8]-[10]. Shakiba [11] in a recent systematic review comparing aspiration and sclerotherapy versus hydrocelectomy for treating $\mathrm{VH}$ conclude that postoperative complications as well as cost and time to work resumption were less in the aspiration and sclerotherapy group; however the recurrence rate was higher. When hydrocele is voluminous it can be crippling. It can cause significant discomfort during sexual intercourse. VH can appear then as a disease which impedes self-esteem because it touches the symbol of male virility [6].

The simple puncture-aspiration of hydrocele is not effective. VH usually idiopathic will recur later and the patient will need a new puncture. Iterative punctures of hydrocele fluid should be avoided because they expose to complications such infection which may progress to necrosis of scrotum or testicular necrosis. This is the case in two of our patients in whom we performed a unilateral orchiectomy. This could compromise the patient's fertility. Simple Puncture and aspiration is a worthy option because of the high recurrence rate. Puncture is less expensive for the patient than hydrocelectomy but the management of its complications can be even more expensive as demonstrate in this study.

\section{Conclusion}

Hydrocelectomy remains the gold standard of the treatment of idiopathic hydrocele in our opinion. It must be done carefully to avoid postoperative complications. As for puncture, it must be avoided because of the risk of infection and high recurrence rate.

\section{Conflict of Interest}

None.

\section{References}

[1] Jayakarthik, Y. and Patil, M.B. (2015) Comparative Study of Efficacy of Injection Sclerotherapy versus Surgery as Primary Modality Therapy in Primary Vaginal Hydrocoele: A Randomised Control Study. Journal of Evolution of Medical and Dental Sciences, 4, 1405-1413. http://dx.doi.org/10.14260/jemds/2015/198

[2] Jat, N., Bano, F., Memon, I.A., Memon, M.S. and Azmi, M.A. (2014) Primary Vaginal Hydrocele; Different Surgical Procedures: A Comparative Study. The Professional Medical Journal, 21, 879-882.

[3] Ahmad, T., Ullah, S., Nabi, G., Ullah, N. and Rahman, K. (2014) A Mini Review on Hydrocele: The Most Common Scrotal Problem. Social and Basic Sciences Research Review, 2, 571-575.

[4] Savita, K.S. (2014) Hydrocele Management in a Filaria Endemic Area. Indian Journal of Basic and Applied Medical Research, 4, 447-450.

[5] Sagar, J., Kumar, S., Mondal, D. and Shah, D.K. (2006) Idiopathic Infected Hydrocele in a Toddler: A Case Report with Review. TSW Urology, 1, 101-103. http://dx.doi.org/10.1100/tsw.2006.371

[6] Gyapong, M., Gyapong, J., Weiss, M. and Tanner, M. (2000) The Burden of Hydrocele on Men in Northern Ghana. 
Acta Tropica, 77, 287-294. http://dx.doi.org/10.1016/S0001-706X(00)00145-5

[7] Ahorlu, C.K., Dunyo, S.K., Asamoah, G. and Simonsen, P.E. (2001) Consequences of Hydrocele and the Benefits of Hydrocelectomy: A Qualitative Study in Lymphatic Filariasis Endemic Communities on the Coast of Ghana. Acta Tropica, 80, 215-221. http://dx.doi.org/10.1016/S0001-706X(01)00159-0

[8] Tariel, E. and Mongiat-Artus, P. (2004) Traitement des hydrocèles de l'adulte. Annales d'Urologie, 38, 180-185. http://dx.doi.org/10.1016/j.anuro.2004.05.002

[9] Zampieri, N., El-Dalati, G., Ottolenghi, A. and Camoglio, F.S. (2009) Percutaneous Aspiration for Hydroceles after Varicocelectomy. Urology, 74, 1122-1124. http://dx.doi.org/10.1016/j.urology.2009.01.079

[10] Shan, C.J., Lucon, A.M., Pagani, R. and Srougi, M. (2011) Sclerotherapy of Hydroceles and Spermatoceles with Alcohol: Results and Effects on the Semen Analysis. International Brazilian Journal of Urology, 37, 307-313. http://dx.doi.org/10.1590/S1677-55382011000300003

[11] Shakiba, B., Heidari, K., Jamali, A. and Afshar, K. (2014) Aspiration and Sclerotherapy versus Hydrocelectomy for Treating Hydroceles. Cochrane Database of Systematic Reviews, 11, CD009735. 